\title{
〈原著論文〉
}

\section{Genetic Aspects for Fatty Acid Components of Adipose Tissues in Syrian Hamster}

\author{
Yoshihito Suda, Hisashi Shinohara, Toshiyasu Yamaguchi \\ and Toshihiro Yamagishi
}

\section{The Graduate School of Agricultural Science, Tohoku University, Tsutsumidori Amemiya-machi 1-1, Aoba-ku, Sendai-shi, Miyagi, 981-8555, Japan, Tel:+81-0-22-717-8695, Fax:+81-0-22-717-8697, E-mail: asuda@mail.ecc.u-tokyo.ac.jp}

\section{Abstract}

To study the genetic aspects of fatty acid components in adipose tissues of Syrian Hamsters, a total of ninety animals of three lines were used. One inbred line (GN) was always fed cereals (Diet F) and inbred to the closed herd. Another selected line (ALF) was always fed with alfalfa meal pellet (Diet A) and selected to increase the weaning number. Another control line (GNR) was mated at random, with one of its group always fed cereals without selecting for litter size, and the second group fed an alfalfa pellet. Adipose tissues were taken from three parts of the subcutaneous round of back legs, round of kidney and generative organs. Rates of fatty acid components of total lipids extracted from their tissues were determined by Gas Chromatography and compared statistically to average out random effects of the line, sex, age in weeks, body part and diet. To research for genetic variation of fatty acid components and $\Delta 9$-desaturase activity index $(\Delta 9$-desat.), genetic parameters of each effect were estimated.

ALF seems to increase the animal's productive ability of C18:1, a measure of the efficiency of biosynthesis for mono-unsaturated fatty acids(MUSFA). So, ALF might be introducing a genetic variation by increasing the capacity to make use of energy in reproductive behavior. Estimated heritabilities of 
MUSFA and 49 -desat. were 0.73 and 0.61 respectively. Estimated genetic correlation between total saturated fatty acid(SFA) and MUSFA or 49 -desat. were negative values. Considering the circumstances mentioned above, amounts of fatty acid components in adipose tissues of every part might be induced to genetically. To determine that, it might be useful to use $\Delta 9$-desat. as an indicator.

KEY WORDS: syrian hamster $\cdot$ alfalfa $\cdot$ fatty acid $\cdot$ heritability $\cdot$ genetic correlation (Received:April 18,2001; Aecepted: July 24,2001)

\section{Introduction}

Recently, for evaluation of meat quality, it is known to be important to research the fatty acid components of total lipids in adipose tissues and muscle. However, it is not clear what factors affected the fatty acid components. So, research of the genetic variations will not account for the full effect. Especially, in today's Japan, it is impossible to make a meat which include high rate of total unsaturated fatty acid (USFA) without feeding much the cereals imported from the other country. So it is important to improve the strains genetically and increase their adipose tissues and muscles by considering many factors $^{1,2,3,4,5,6,7)}$.

Syrian Hamster is a grassing animal that has two stomachs. A fore-stomach has specific fungi stocks that produce some volatile fatty acids (VFA) and a back-stomach that secretes some digestive enzymes. Also, they have simple fatty acid components that most resemble those of beef cattle ${ }^{8)}$. So, for their structural and functional aspects, they resemble other ruminant animals, and can thus be examined easily without economic loss instead of large sized ruminants ${ }^{9}$.

In the future, improvement of meat quality is important for a suitable response to many requests from the market. But, there is only one published report for genetic aspects of the fatty acid components in adipose tissues of meat ${ }^{10,11,12)}$. Since genetic parameters are population attributes that require large data sets involving the lengthy laboratory procedures involved in fatty acid analysis, large data sets are hard to come by ${ }^{13)}$. So, in this study, the genetic aspects of 
fatty acid components in adipose tissues were researched by estimation of genetic ;parameter, the $\Delta 9$-desaturase activity index ( $\Delta 9$-desat.) using the three lines of Syrian Hamster as examples of the ruminant animals.

In the study, the fatty acid components in adipose tissues of lines that were selected toward increasing fertilized ability under feeding with an alfalfa pellet and an unselected line were compared respectively. Genetic differences for fatty acid components, therefore, were discussed. The possibility to improve the herd genetically with crude diets and produce meat that has more acceptable fatty acid components in animal production was researched ${ }^{14)}$.

\section{Materials and Methods}

\section{Animals and Management}

A total of ninety Syrian Hamsters of three lines were used in this study. The one line was GNR that was maintained with random mating in the closed herd during fifty-two generations. And the second line was GN that was maintained during one hundred forty eight generations with mating between siblings of GNR line in closed herd. And the third line was ALF that was produced by selecting during forty generations toward increasing number able to wean mating between siblings of GNR in closed herd fed the alfalfa leaf pellet (Diet A): Every number and the construction and feeding condition of comparison group are shown in the Table 1.

Table 1.

Construction and number for the experimental animal

\begin{tabular}{cccc}
\hline Line & Diet & Male & Female \\
\hline GN & A & 10 & 10 \\
& F & 10 & 10 \\
ALF & A & 10 & 10 \\
& F & 10 & 10 \\
GNR & A & 5 & - \\
& F & 5 & - \\
\hline
\end{tabular}

DietA:alfalfa meal pellet, DietF:Cereal diet for laboratory animals 
GNR and GN lines were always fed ad libitum cereal (Diet F). ALF line was fed ad libitum Diet A. Tap drinking water was always freely available for each animal. Each ten heads of male and female on GN were fed on Diet A from starting of weaning. Residual animals of GN were given Diet A. Also, each ten heads of male and female on ALF were fed on Diet F from starting of weaning. Residual animals of ALF were given Diet F. And five of GNR were fed continuously on Diet A and residuals were given Diet F.

\section{Sampling of Tissues Preparation}

Animals were slaughtered by absorbing ether. Adipose tissues in the carcass of animals were taken from subcutaneous tissue of jointing part of back legs, tissues of the reproductive organ and kidney of round at the age of three weeks (weaning period), eight and thirteen weeks as point of maturing. Obtained samples were stored at $-20^{\circ} \mathrm{C}$ until analyzing them.

\section{Fatty Acid Component Analysis}

Extraction of total lipid from samples (10mg) was carried out by the method of Folch et $a^{15}$. They were methylated in $600 \mu \mathrm{l}$ methanol-choleric acid for 20 second. at $50^{\circ} \mathrm{C}$. The fatty acid methylated esters were extracted by hexane and analyzed using a dual column gas chromatograph (HITACHI 163, Japan) equipped with a glass column (J\&W DB-23). The injection port and detector temperature was $215^{\circ} \mathrm{C}$. The oven temperature was $100^{\circ} \mathrm{C}$. The flow rate of nitrogen was $6 \mathrm{~kg} / \mathrm{min}$. A standard of known composition was analyzed to verify the identity of fatty acids in the samples. The fatty acids peak areas were quantified with an electric integrator (C-R6A, Chromatopac, Shimazu Co., Kyoto, Japan).

\section{Detected Fatty Acids and Calculated Index}

Fatty acids which were detected in this study were myristic acid(C14:0), myristoleic acid (C14:1), palmitic acid (C16:0), palmitoleic acid (C16:1), stearic acid (C18:0), oleic acid (C18:1) and linoeic acid (C18:2). $\triangle$ 9-desat. was calculated using an equation described by Siebert et al. and shown as the ratio of sum of $\mathrm{C} 18: 0$ and $\mathrm{C} 18: 1$ to $\mathrm{C} 18: 1^{16)}$.

\section{Statistical Analysis}

All data were analyzed with least squares analysis of variance using PROC 
GLM Type III Sums of Squares of SAS ${ }^{17)}$. The model for analysis of variance of all data was

$$
X_{i j k l m n}=\mu+L_{i}+S_{j}+A_{k}+P_{l}+D_{m}+e_{i j k l m n}
$$

where $X_{i j k l m n}$ : data of $1^{\text {th }}$ individual in $t^{\text {th }}$ line, $f^{\text {th }}$ sex, $k^{\text {th }}$ age, $I^{\text {th }}$ part and $m^{\text {th }}$ diet

$$
\begin{aligned}
& \mu: \text { over all mean } \\
& L_{i}: \text { effect of } I^{\text {h }} \text { line } \\
& S_{j}: \text { effect of } f^{\mathrm{h}} \text { sex } \\
& A_{k}: \text { effect of } k^{\text {th }} \text { age } \\
& P_{l}: \text { effect of } H^{\mathrm{h}} \text { part } \\
& D_{m}: \text { effect of } m^{\text {th }} \text { diet } \\
& e_{i j k l m n} \text { : random error in } X_{i j k l m n} .
\end{aligned}
$$

SFA was a sum of each ratio of saturated fatty acids. USFA was a sum of each ratio of unsaturated fatty acids. PUSFA was a sum of each ratio of monounsaturated fatty acids, and MUSFA was a sum of polyunsaturated fatty acids.

Heritabilities and genetic correlations as genetic parameters were computed by multiple trait derivative free restricted maximum likelihood computer program (MTDFREML) of Boldman et al. ${ }^{18)}$ with genetic mixed model of animal model. In matrix notation, the genetic mixed model for an observation vector, $\mathrm{Y}$, is

$$
\mathrm{Y}=\mathrm{X} \beta+\mathrm{Zu}+\mathrm{e} \text {, where }
$$

$\beta=$ vector of fixed effects of line, age and diet in $Y$ by $X$,

$\mathrm{u}=$ vector of random effects associated with the additive genetic effect for fatty acid components in $\mathrm{Y}$ by $\mathrm{Z}$, and $\mathrm{e}=$ vector of residuals that were impossible to explain as an effective factor.

\section{Results}

\section{Chemical components of the experimental diets}

The chemical composition (\%) of the experimental diets is shown in Table 2. The nitrogen free extract of $65 \%$ in Diet $F$ was at a 
Table 2.

Chemical composition of the experimental $\operatorname{diets}(\%)$

\begin{tabular}{|c|c|c|}
\hline & $\operatorname{Diet} A$ & Diet F \\
\hline Dry material(DM) & 91.6 & 93.3 \\
\hline Crude protein & 18.7 & 21.7 \\
\hline Crude fat & 3.5 & 5.3 \\
\hline NFE & 44.5 & 65.3 \\
\hline $\mathrm{ADF}$ & 24.1 & 3.0 \\
\hline Crude ash & 9.1 & 4.4 \\
\hline Calcium & 1.8 & 0.6 \\
\hline Phosphorus & 0.2 & 0.6 \\
\hline Magnesium & 0.4 & 0.2 \\
\hline NDF & 52.4 & 15.5 \\
\hline
\end{tabular}

high level as compared to $44.5 \%$ in Diet A. Crude fiber of $24 \%$ in Diet A was higher in level than $3.0 \%$ in Diet F. Crude ash in Diet A was about two times that of Diet F. The mineral component of calcium and magnesium in Diet $\mathrm{A}$ comprised about twice that of Diet F. Additionally, the total fiber of $52.4 \%$ in Diet A was much higher than $15.5 \%$ for Diet $F$.

\section{Fatty acids components of contained in the experimental diets}

Fatty acid components for the lipids contained in the two diets are shown in Table 3. The Diet A contained 15.1\% C16:0 of SFA, but Diet F did not. Diet F

Table 3.

Fatty acid components(\%) of lipid contained in diets

\begin{tabular}{ccc}
\hline Fatty acid & Diet A & Diet F \\
\hline C14:0 & 0.60 & 0.40 \\
C14:1 & 0.30 & 0.13 \\
C16:0 & 15.07 & (trace) \\
C16:1 & 0.90 & 13.72 \\
C18:0 & 12.47 & 25.27 \\
C18:1 & 19.83 & 51.10 \\
C18:2 & 37.87 & 5.07 \\
C18:3 & 7.27 & 1.27 \\
SFA & 28.14 & 25.67 \\
USFA & 66.17 & 71.29 \\
\hline
\end{tabular}

SFA:Total saturated fatty acids,USFA:

Total unsaturated fatty acids, DietA:alfalfa meal pellet, DietF:Cereal diet for laboratory animals 
had contained some kinds of high level USFA, but, in Diet A, C18:2 and C18:3 were present in higher levels at $37.9 \%$ and $7.3 \%$, respectively, than those of Diet F, 71.3\%, was higher in level than that of Diet A, 66.2\%. So, considering various fatty acid components, the specific kinds that were part of the rich USFA in both diets differed a great deal.

\section{Analysis of variances for fatty acid components etc.}

Analysis of variance for the fatty acid component ratios is shown in Table 4 . The effect of breeding line was significant for $\mathrm{C} 16: 1(\mathrm{P}<0.001), \quad \mathrm{C} 18: 0(\mathrm{P}<0.01)$,

Table 4.

Analysis of variances for fatty acid components and 49-desat. in adipose tissues of Syrian Hamsters

\begin{tabular}{|c|c|c|c|c|c|}
\hline & Line & Sex & Age & Part & Diet \\
\hline $\mathrm{C} 16: 0$ & ns & * & ns & $\mathrm{ns}$ & * \\
\hline $\mathrm{C} 16: 1$ & $* * *$ & ns & ns & * & $* * *$ \\
\hline C $18: 0$ & $* *$ & ns & ns & ns & ns \\
\hline C18:1 & $* *$ & ns & $* * *$ & ns & * \\
\hline C18:2 & ns & ns & ns & $* *$ & $* *$ \\
\hline C18:3 & $* * *$ & ns & $* * *$ & $* * *$ & $* * *$ \\
\hline SFA & ns & $\mathrm{ns}$ & $* * *$ & ns & $* *$ \\
\hline USFA & ns & * & ns & ns & ns \\
\hline $\mathrm{U} / \mathrm{S}$ & ns & * & * & ns & * \\
\hline MUSFA & $* * *$ & ns & $* * *$ & ns & ns \\
\hline PUSFA & $* * *$ & ns & $\mathrm{ns}$ & ns & ns \\
\hline$\Delta 9$-desat. & $* * *$ & ns & $* * *$ & ns & * \\
\hline $\mathrm{C} 18: 1 / 18: 0$ & * & ns & $\mathrm{ns}$ & $\mathrm{ns}$ & ns \\
\hline
\end{tabular}

SFA:Total saturated fatty acids, USFA:Total unsaturated fatty acids, U/S:USFA/SFA, MUSFA:Total monounsaturated fatty acids, PUSFA:Total polyunsaturated fatty acids, $\Delta$ 9-desat.: $\triangle 9$-desatursase activity index $(=\mathrm{C} 18: 1 /(18: 1+18: 0))$, $*: \mathrm{P}<0.05, * *: \mathrm{P}<0.01, * * *: \mathrm{P}<0.001$, ns:ns letters are not significant

C18:1(P<0.01), C18:3(P<0.001), MUSFA $(\mathrm{P}<0.001), \quad \mathrm{PUSFA}(\mathrm{P}<0.001), \quad \triangle$ 9-desat. $(\mathrm{P}<0.001)$ and $\mathrm{C} 18: 1 / \mathrm{C} 18: 0(\mathrm{P}<0.05)$. The effect of hamster age was significant, highly, for $\mathrm{C} 18: 1(\mathrm{P}<0.001), \mathrm{C} 18: 3(\mathrm{P}<0.001), \quad \mathrm{SFA}(\mathrm{P}<0.001)$, $U / S(P<0.05)$, MUSFA $(P<0.001)$ and 49 -desat $(P<0.001)$. The effect of body part was significant for $\mathrm{C} 16: 1(\mathrm{P}<0.05), \mathrm{C} 18: 2(\mathrm{P}<0.01)$ and $\mathrm{C} 18: 3(\mathrm{P}<0.001)$. The effect of the type of diet was significant for $C 16: 0(P<0.05), C 16: 1(P<0.001)$, 
$\mathrm{C} 18: 1(\mathrm{P}<0.05), \mathrm{C} 18: 2(\mathrm{P}<0.01), \mathrm{C} 18: 3(\mathrm{P}<0.001)$ and $\mathrm{SFA}(\mathrm{P}<0.01), \mathrm{U} / \mathrm{S}(\mathrm{P}<0.05)$ and 49 -desat. $(\mathrm{P}<0.05)$.

\section{Differences between lines for calculated index on fatty acid components}

SFA, USFA, MUSFA and PUSFA at the age of ten weeks for animals fed on Diet $A$ and Diet $F$ in three lines out of all the lines are shown in Table 5 . and Table 6., respectively. When Diet F was fed to all lines until the age of ten

Table 5.

Least square of means(\%) and standard errors of fatty acid components in adipose tissues of GN, ALF and GNR at the age of ten weeks fed to Diet $F$

\begin{tabular}{cccc}
\hline & GN & ALF & GNR \\
\hline SFA & $23.2(0.3)$ & $25.7(0.3)$ & $23.6(0.3)$ \\
USFA & $75.3(0.3)^{\mathrm{a}}$ & $72.2(0.2)^{\mathrm{b}}$ & $76.0(0.3)^{\mathrm{a}}$ \\
MUSFA & $50.0(0.9)^{\mathrm{b}}$ & $51.7(0.8)^{\mathrm{b}}$ & $56.7(0.8)^{\mathrm{a}}$ \\
PUSFA & $25.2(0.3)^{\mathrm{a}}$ & $21.1(0.4)^{\mathrm{b}}$ & $26.3(0.3)^{\mathrm{a}}$ \\
\hline SFA:Total saturated fatty acids, USA:Total unsaturated \\
fatty acids, MUSFA:Total monounsaturated fatty \\
acids, PUSFA:Total polyunsaturated fatty acids, \\
DietF:Cereal diet for laboratory animals, ( ):Standard error \\
Different superscripts between lines is significant \\
in the same low $(\mathrm{P}<0.05)$.
\end{tabular}

Table 6.

Least square of means $(\%)$ and standard errors of fatty acid components in adipose tissues of GN, ALF and GNR at the age of ten weeks fed to Diet A

\begin{tabular}{cccc}
\hline & GN & ALF & GNR \\
\hline SFA & $34.0(0.3)^{\mathrm{a}}$ & $24.5(0.3)^{\mathrm{b}}$ & $30.3(0.4)^{\mathrm{b}}$ \\
USFA & $55.2(0.2)^{\mathrm{b}}$ & $71.0(0.2)^{\mathrm{a}}$ & $69.5(0.3)^{\mathrm{a}}$ \\
MUSFA & $12.1(0.9)^{\mathrm{c}}$ & $36.0(0.8)^{\mathrm{a}}$ & $29.2(0.8)^{\mathrm{b}}$ \\
PUSFA & $27.0(0.3)^{\mathrm{b}}$ & $36.8(0.3)^{\mathrm{a}}$ & $41.1(0.3)^{\mathrm{a}}$ \\
\hline
\end{tabular}

SFA:Total saturated fatty acids, USA:Total unsaturated fatty acids, MUSFA:Total monounsaturated fatty acids, PUSFA:Total polyunsaturated fatty acids, DietA:alfalfa meal pellet, ():Standard error Different superscripts between lines is significant in the same low $(\mathrm{P}<0.05)$. 
weeks, MUSFA tended to increase on ALF. And 49 -desat. was highest in ALF, but the differences of means between GN and ALF was not significant on MUSFA. This was because USFA of ALF was lowest of three lines, significantly. There were not significant differences between GN and ALF, but ALF tended to increase the biosynthesis ability of MUSFA. So, $\triangle 9$-desat. of ALF had been high level, compared to the other lines $(\mathrm{P}<0.01)$. Generally, $\mathrm{C} 18: 1$ is a high ratio in mammalian adipose tissues, that is, more than $\mathrm{C} 16: 1$ in the composition of feeding in both diets. So, occupied MUSFA in total ratio of fatty acid components was highest percentage. Also when GN was fed with Diet A, MUSFA was significantly low $(\mathrm{P}<0.01)$. But, for ALF and GNR, the difference between their means was not significant.

\section{To estimate genetic parameter of calculated index on fatty acid components}

To determine statistically the genetic influences of SFA, USFA, MUSFA, PUSFA, 49 -desat. and C18:1/C18:0 in adipose tissues, genetic parameters for each were estimated using the MTDFREML computer program by Van Veleck et $a l^{18)}$. To estimate these parameters, a genetic mixed model that contained the fixed effect of line, age, diet and the additive genetic effects from sire and dam as the random effect was used. Their estimated parameters are shown in Table 7. Heritabilities of SFA, USFA, MUSFA, and C18:1/C18:0 were 0.22,

Table 7.

Estimated genetic parameters of SFA, USFA, MUSFA, PUSFA, 49 -desat. and C18:1/18:0

\begin{tabular}{ccc}
\hline & Heritability & Genetic correlation \\
\hline SFA & 0.22 & $(1.00)$ \\
USFA & 0.60 & -0.34 \\
MUSFA & 0.73 & -0.27 \\
PUSFA & 0.30 & -0.85 \\
D9-desat. & 0.61 & -0.88 \\
C18:1/C18:0 & 0.27 & -0.88 \\
\hline
\end{tabular}

SFA:Total saturated fatty acids, USA:Total unsaturated fatty acids, MUSFA:Total monounsaturated fatty acids, PUSFA:Total polyunsaturated fatty acids, $\triangle 9$-desat.: $\triangle 9$-desatursase activity index $(=\mathrm{C} 18: 1 /(\mathrm{C} 18: 1+\mathrm{C} 18: 0))$ 
$0.60,0.73$ and 0.27 , respectively. And, for $\triangle 9$-desat., heritabilit was estimated at 0.61 . The genetic correlation among USFA, MUSFA, PUSFA, 19 -desat., C18:1/C18:0 with SFA was estimated to be $-0.34,-0.27,-0.85,-0.88$ and -0.88 , respectively.

\section{Discussion}

The components of the lipids in adipose tissues are mainly triglycerides. And C18:1 contained the richest amount of triglyceride and tended to increase, slightly, with age of animal on our information from nonpublic reports. Because the ratio of $\mathrm{C} 18: 1$ in a triglyceride was different significantly between the three lines, the significance for genetic effect was predicted as a biosynthesis ability of C18:1. That is, USFA might be able to reflect the genetic variance. Additionally, considering the effect of diet, the interaction between diet and line must be researched to reveal its genetic aspects. Suda et al. reported in other research that a relationship between the effect of diet and line revealed a change in fatty acid components in adipose tissues ${ }^{19)}$. However, the relationship was not quantifiable, significantly, between both effects in that study. The effect of diet has been known to be a factor that might influence the fatty acid components. It was reported that diet had an influence on the rumen microbial population in vivo and in vitro ${ }^{8}$. That investigation agreed with the results of this examination. Most of lipids in the diet are absorbed in the intestine. The C18:1 has inserted a double bond at the $\triangle 9$-position in C18:0, so synthesized by $\Delta 9$-desat. in the liver or alternative it is absorbed from the diet and stored along with the other triglyceride components. $\Delta 9$-desaturase activity or the expression of a gene coding the enzyme might be able to estimate this genetic variance, because the effect of line was significant for $\mathrm{C} 18: 1(\mathrm{P}<0.01)$ and, highly, for MUSFA $(P<0.001)$, PUSFA $(P<0.001)$. Also, because the effect of breeding line was significant for $\mathrm{C} 18: 0$, the influence for bio-synthesis to $\mathrm{C} 18: 1$ might significantly vary significantly the fatty acid components in adipose tissues. So, to reveal the interaction between the effect of diet and line is very difficult and complex, but the concept of a peptide of a specific enzyme synthesizing MUSFA affecting the absorption of lipids must be easy to 
understand.

In this study, an index for C18:1 on animals fed Diet F until the age of ten weeks was $47.8 \%$ in GN, 45.1\% in ALF and 46.5\% in GNR. And C18:1 for ones fed Diet A were $15.4 \%$ in GN, 30.4\% in ALF and 26.8\% in GNR. Considering the results and views mentioned above, the ALF line might be able to reproduce under the feeding condition of low energy. And they might get a high demanding volume of the diet according to increasing biosynthesis of USFA for the energy efficiency in vivo, because the selected line to increase the weaning number for reproduction was fed Diet $\mathrm{A}$. Reed et al. reported that a sift in energy supply from forage to concentrate had a minimal effect on digestion and reproduction in first-calf beef heifer ${ }^{21)}$. So, it is necessary to research the demanding volume of their diets. The synthesis ability of the animals for MUSFA might be increased indirectly, using selection to increase their reproductive ability under the feeding condition of the crude diet. However, in the line without the selection, GNR, the fact that SFA, USFA, and PUSFA were the same level might indicate that the GN line was fitted to a high energy diet, genetically.

Therefore, considering the significant difference between ALF and GN on USFA, MUSFA and $\triangle 9$-desat., USFA and MUSFA might be altered by working with genetic factors. Also, they might be able to be used to select for genetic improvement of the fatty acid components, and that would be an important factor to improve the meat quality. Especially, C18:1 and 49 -desat. should be noted as efficient indicators. 49 -desaturase has been recognized as a enzyme that synthesizes C18:1 in vivo or in vitro. So, if $\Delta 9$-desat. has a large genetic variance, its level could be increased, and one many thus hope to realize a genetic gain. In this research, because heritability of $\Delta 9$-desat. was estimated at 0.61 , a genetic gain will be realized gotten by selection using 49 -desat. as a index. However, the relationships between each of the fatty acids in many tissues are very complicated, both phenotypically and genetically. Therefore, correlations for each of them have to be considered, to improve the normal valance without producing an abnormal state. The estimated genetic correlation between USFA and SFA was -0.34 . So, to proceed towaed improvement by 
decreasing SFA, we suggest that it is best to increase USFA in adipose tissues, and that might be able to realized. This might closely associate to the estimated(-0.88) genetic correlation between $\triangle 9$-desat. and SFA. The genetic change of each fatty acid component depends on the genetic variation of desaturase activity. But, biologically, the degree that USFA can be increase in adipose tissues must only be accomplished in vivo.

Considering the views mentioned above, a result that the selected line, ALF included better MUSFA than the other lines suggests that we are able to improve the fatty acid components genetically by using 49 -desat. or USFA, indirectly. Realistically, in the case of animals of which will born many pups per one progeny, to select the full sibs would be most efficient, while, in case of beef cattle, the selection in half-sibs would still be useful. Four beef cattle, it was reported that the fatty acid components in adipose tissues differ between the breeds ${ }^{20)}$. The ability to use fatty acids as the energy source might differ between lines or breeds with a different genetic background. So, it is important for the meat quality to be improved by using $\triangle 9$-desat. and USFA as the indicators.

\section{Acknowledgements}

This study indicates clearly that line, age and diet are important factors for significant variance of fatty acid components in adipose tissues. Because the Syrian Hamsters used in this study were under the same management conditions, these results suggest that some factors of genetic import are the differences of the fatty acid components in them. Especially, the variance by an effect of line might be as high as it is for the diet, so the genetic character of fatty acid components in them would be related by information from the interactions between the two effects.

We think that, because this may be controlled by a few environmental factors, one would be able to make the desired traits in meat quality without the effect of diet using the genetic technique of selection, but alfalfa diet produces better meat quality and should also in cattle. 


\section{References}

1) Fisher H, Holland KG, Weiss HS. Environmental temperature and composition of body fat. Proc. Sco. Exp. Biol. Med. 110:1832-1838, 1962.

2) Ito M. Molecular species compositions of triacylglycerols of subcutaneous fat, and their association with total lipids content of M.longissimus thoracis of fattened beef cattle. Anim.Sci.Tech. 68(12):1118-1126, 1997.

3) Cramer DA, Marchello JA. Seasonal and sex patterns in fat composition of growing lambs. J.Anim.Sci. 23:1002-1008, 1964.

4) David BW, Hedrick HB. 1979 Fatty acid composition of bovine lipids as influenced by diets, sex and anatomical location and relationship to sensory characteristics. J.Anim.Sci. 48(6):1343-1348, 1979.

5) Zembayashi M, Nishimura K, Lunt DK, Smith SB. Effect of breed type and sex on the fatty acid composition of subcutaneous and intramuscular lipids of finishing steers and heifers. J. Anim. Sci. 73:3325-3332, 1995.

6) Mao LHE, Sang SR. The relationship between fatty acid composition and the size of adipocytes from subcutaneous adipose tissues of holstein steers during the fattening period. Jpn. J. Anim.Sci. Tech. 68(9):838-842, 1997.

7) Miller RH, Smith JW, Harvey WR, Creegan ME. Modified regression for estimating total lactation from part-lactation yield. J. Dairy Sci. 55:208-214, 1972.

8) Slyter LL, Putnam PA. In vivo vs In vitro continuous culture of ruminal microbial populations. J.Anim.Sci. 26:1421-1426, 1967.

9) Frederich RE, Richard GW. Nutritional implications of the hamster forestomach. J.Nutr. 108:1647-1053, 1978.

10) Lori CSJ, Lunt DK, Smith SB. Fatty acid elongation and desaturation enzyme activities of bovine liver and subcutaneous adipose tissues microsomes. J.Anim.Sci. 69:1064-1073, 1991.

11) Eisaku T. Changes in fatty acid composition of depot fat and muscle in steers fattened by concentrate feeding after grazing. Jpn. J.Zootech. Sci. 60(4):315-320, 1989. 
12) Gillis AT, Eskin NA. Fatty acid composition of bovine intramuscular and subcutaneous fat as related to breed and sex. J.Food Sci. 38:408-412, 1973.

13) Falconer DS, Mackay TFC. Introduction to quantitative genetics (fourth edition). England: Longman group ltd. 1996.

14) Malau AEO, Siebert BD, Pitchford WS. Breed comparison of the fatty acid composition of muscle phospholipids in Jersy and Limousin cattle. J.Anim.Sci. 76:766-773, 1998.

15) Folch J, Less M, Saloane SGH. A simple method for the isolation and purification of total lipids from animal tissues. J. Biol. Chem. 226:497-509, 1957.

16) Siebert BD, Malau AEO, Deland MPB, Bottema CDK, Pitchford WS. Genetic variation between crossbred weaner calves in triglyceride fatty acid composition. Proc.W. Congr.Gen.Appl.Livest. Prod. 25:177-180, 1998.

17) SAS Ins Inc. SAS Users Guide (version 6) ; Statistics. Cary NC, 1989.

18) Boldman KG, Kriese LA, Van-Veleck LD, Kachman SD. A manual for USE of MTDFREML, 1993.

19) Suda $Y$, Shinohara H, Takahashi M, Suzuki Y, Yamagishi T. Estimation of genetic parameter for fatty acid components on adipose tissue in Syrian Hamster. Exper.Herb. 22:47-54, 1998.

20) Malau AEO, Siebert BD, Bottema CDK, Deland MPB, Pitchford WS. Heritabilities of triglyceride fatty acids from the adipose tissues of beef cattle at weaning and slaughter. Proc.W.Congr. Gen. Appl. Livest.Prod. 25:181-184, 1998.

21) Reed BK, Hunt CW, Sasser RG, Momont PA, Rode LM, Kastelic JP. Effect of forage:concetratie rate on digestion and reproduction in primiparous beef heifer. Journal of Anim. Sci. 75(7):1708-714, 1997. 